\title{
Stem cell-derived exosomes: a novel vector for tissue repair and diabetic therapy
}

\author{
William C Newton', Joseph W Kim', John Z Q Luo',2, and LuGuang Luo' \\ 'Department of Medicine, The Center of Stem Cell Biology, Roger Williams Hospital, Boston University, \\ School of Medicine, Providence, Rhode Island, USA \\ IInsure Health, Inc., Warwick, Rhode Island, USA
}

Correspondence should be addressed to L Luo Email Igluo@bu.edu

\begin{abstract}
Exosomes are extracellular vesicles (EVs) secreted from a majority of cell types. Exosomes play a role in healthy and pathogenic intercellular interactions via the transfer of proteins, lipids and RNA. The contents and effects of exosomes vary depending on the properties of the originating cell. Exosomes secreted from some cell types, including stem cells, carry biological factors implicated in the protection, regeneration and angiogenesis of damaged tissues. Due to these properties, exosomes have attracted attention as a novel vector for regenerative therapies. Exosomes as a therapeutic tool could have applications for the treatment of many disorders characterized by chronic tissue damage. Exosomes derived from stem cells could be applied to repair or prevent damage from the complications of diabetes mellitus. The immunomodulatory and reparative properties of stem cell-derived exosomes could protect or even restore an early-stage type 1 diabetic patient's original islets from autoimmune destruction. Exosomes could also possibly suppress graft rejection of pancreatic islet transplants. Therefore, it is our recommendation that the treatment of diabetes mellitus using exosome-based therapies be further explored. Development of novel therapies using exosomes is slowed by a limited understanding of their mechanisms. This hurdle must be overcome to pave the way for clinical trials and ultimately the adaptation of exosomes as a therapeutic vector.
\end{abstract}

Journal of Molecular Endocrinology (2017) 59, R155-R165

\section{Introduction to exosomes}

It has long been reported that cells release vesicles into the intercellular space (Simons \& Raposo 2009, Schneider \& Simons 2013). These extracellular vesicles (EVs) take several forms, characterized by size and the process by which they are formed. There are three known types of EVs: apoptotic bodies, microvesicles and exosomes. Apoptotic bodies (ABs) and microvesicles (MVs), collectively known as shedding vesicles or ectosomes, are released by budding from a cell's plasma membrane (Raposo \& Stoorvogel 2013, Cocucci \& Meldolesi 2015).
Exosomes, a third type of EV, are released from cells via the exocytosis of intraluminal vesicles (ILVs). Exosomes are generally smaller than ectosomes and more uniform in shape (Corrado et al. 2013). This review primarily focuses on exosomes, although it must be noted that a significant overlap in characterization exists between exosomes and other EVs, causing the nomenclature to be inconsistent among publications (Raposo \& Stoorvogel 2013). As a result, many of the studies cited in this article make no distinction between exosomes and other EVs.
() 2017 Society for Endocrinology Printed in Great Britain 
Exosomes were first identified in a study by Harding and coworkers in 1983. Pan \& Johnstone also independently published findings identifying exosomes that same year (Pan \& Johnstone 1983). These vesicles were initially thought to represent a novel mechanism for cells to dispose of unwanted proteins (Kalra et al. 2016). This changed in 1996 when Raposo and coworkers observed that exosomes released by antigen-presenting cells displayed MHC class-II capable of triggering a T-cell response (Raposo et al. 1996). In the following years, exosomes were linked to other forms of cell-cell communication in a variety of cell types (Simons \& Raposo 2009, Schneider \& Simons 2013, Yáñez-Mó et al. 2015). Notably, exosomes have been found to transfer functional RNA between cells (Deregibus et al. 2007, Valadi et al. 2007, Lee et al. 2012, Tomasoni et al. 2013). Studies have found that genetic material, particularly miRNA and mRNA, and proteins found within exosomes derived from certain stem cells can aid in the repair and protection of damaged tissues, generating interest in exosomes as a vector for regenerative therapy (Cantaluppi et al. 2012b, Lee et al. 2012, Tomasoni et al. 2013). In this review, we highlight the clinical significance of exosomes as novel therapeutic vectors for tissue repair and for the treatment of diabetes mellitus.

Exosomes are generated as an alternative endpoint of the endocytic recycling pathway. At the start of this process, an early endosome buds inward from the plasma membrane and is released into the cytoplasm of a cell. Next, intraluminal vesicles (ILVs) pinch inward from the endosomal limiting membrane and bud into the endosome, taking with them a sampling of material from the cytoplasm. The endosome is now a multivesicular body (MVB). Normally the MVB would fuse with a lysosome and its ILVs would be digested. Through unclear mechanisms involving certain Rab GTPases and SNARE proteins (Ostrowski et al. 2010, Bobrie et al. 2011, Raposo \& Stoorvogel 2013), the MVB instead fuses with the plasma membrane, releasing its payload of ILVs into the extracellular medium as exosomes (Alvarez-Erviti et al. 2011, Harding et al. 2013) (Fig. 1).

While many of the general processes of exosome formation and secretion are well understood, many of the specifics remain under investigation (Rak 2010, Corrado et al. 2013). In particular, the molecular mechanisms driving cargo sorting have yet to be fully described. The endosomal sorting complexes required for transport (ESCRT) pathway is believed to play a principal role in this process (Bobrie et al. 2011, Colombo et al. 2013, Cocucci \& Meldolesi 2015). There is also evidence of an ESCRT-independent cargo sorting mechanism requiring ceramide believed to govern the packaging of RNA and certain proteins (Colombo et al. 2013, Schneider \& Simons 2013, Janas et al. 2015). The cargo sorting mechanisms of exosomes are believed to be highly selective as evidenced by the large expression overlap between exosomes of different cellular origins (Guduric-Fuchs et al. 2012).

Exosomes can be identified by their expression of markers associated with membrane transport and fusion, such as Rab GTPases, Annexins and ESCRT 0, I, II and III. MVB biogenesis-associated proteins Alix and TSG101 are also characteristically found within exosomes, along with the tetraspanins CD63, CD9 and CD81 (Zhang et al. 2015). The exosomal membrane is highly enriched

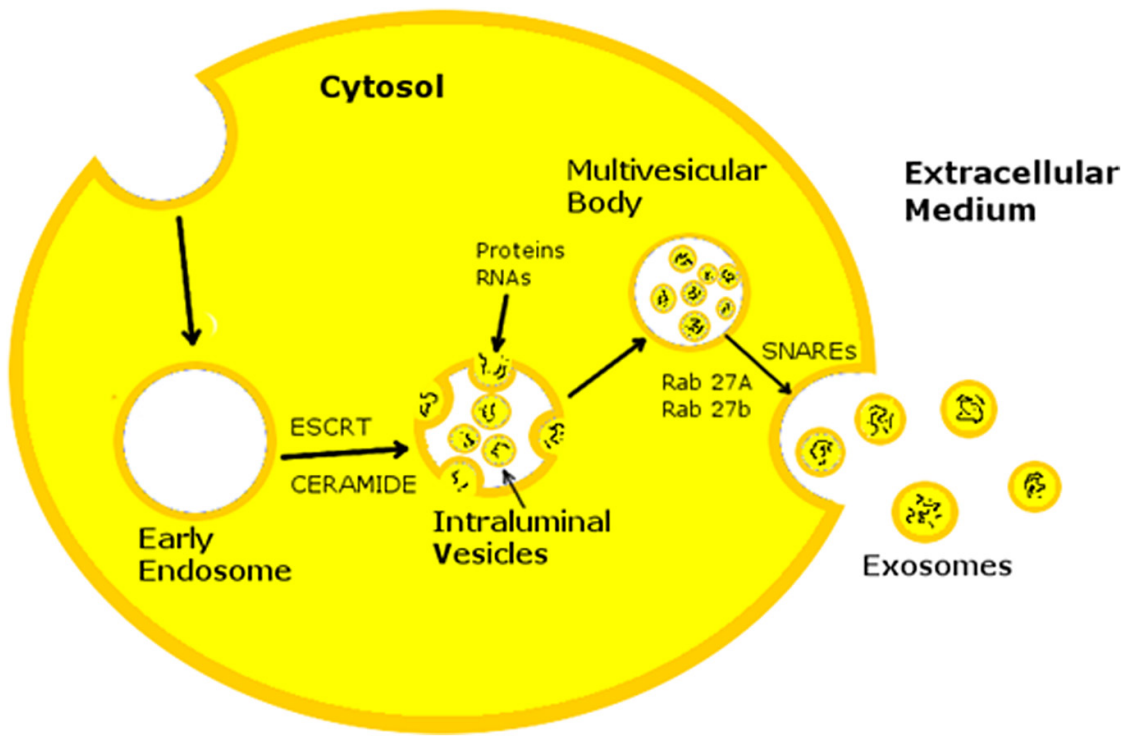

Figure 1

Exosome formation and secretion. The early endosome is formed when a segment of its parent cell's plasma membrane buds inward into the cytosol. Next, the ESCRT and ceramide pathways shuttle proteins and RNA from the cytosol into intraluminal vesicles as they bud into the endosome, forming a multivesicular body (MVB). Rab GTPases guide the MVB to the plasma membrane. SNARE proteins then fuse the MVB with the plasma membrane, releasing the ILVs into the extracellular medium as exosomes. http://jme.endocrinology-journals.org DOI: 10.1530/JME-17-0080
C) 2017 Society for Endocrinology Printed in Great Britain 
in cholesterol, sphingomyelin, hexosylceramides and flotillin, making up structures resembling raft micro domains (Lee et al. 2012, Raposo \& Stoorvogel 2013). Exosomes also commonly express protein and RNA factors unique to their parent cells (Corrado et al. 2013, $\mathrm{Yu}$ et al. 2014). For example, exosomes secreted by dendritic cells express MHC class-II molecules as well as CD80 and CD86 (Morelli et al. 2004, Robbins 2014). The expression profiles of exosomes are also reflective of the conditions of the parent cell, changing in association with a pathogenic state. For example, miR-146b and miR-155, miRNAs known to be upregulated in papillary thyroid cancer cells, can be found overexpressed in exosomes derived from papillary thyroid tumors (Rak 2010, Lee et al. 2015a,b). This attribute makes exosomes a topic of interest as a potential prognostic and diagnostic marker for diseases ranging from cancers to neurodegenerative disorders (Musante et al. 2014, De Toro et al. 2015). To this end, much ongoing research has been dedicated to identifying the specific cargo of exosomes from various sources. Online databases such as VESICLEPEDIA (http:// www.microvesicles.org) and EXOCARTA (http://www. exocarta.org) have been established to allow researchers to post and compare their findings.

Exosomes exhibit unique physical properties that also aid in their characterization. Exosomes range in size from 40 to $100 \mathrm{~nm}$ in diameter and appear in a cupshaped morphology when viewed with negative staining. Although the latter property is caused by the fixation process, these attributes can be used to differentiate these vesicles from other EVs such as MVs and ABs, both of which are generally larger $(50-500 \mathrm{~nm}$ for ABs, $100-1000 \mathrm{~nm}$ for MVs) and appear in various shapes when viewed under an electron microscope (Corrado et al. 2013, Raposo \& Stoorvogel 2013). It must be noted however that overlap exists between vesicle types when it comes to size, shape and even protein content, so properly differentiating types of EVs poses a challenge even to modern techniques (Kastelowitz \& Yin 2014). While electron microscopy, cell flow cytometry, differential centrifugation and immunoassays targeting exosomespecific proteins or lipids have been used to identify and/or isolate different EV types, the number of particles detected in a liter of serum can vary by as many as five orders of magnitude depending on the quantification method used. It is therefore important that standardized techniques be developed for the isolation and sorting of EV subpopulations. Until a standardized characterization technique can be adopted, the functional differences between exosomes and microvesicles will continue to be unclear, and the clinical application will remain difficult.

\section{Exosomes as vehicles for cell-cell communication}

Intercellular communication is a well-documented phenomenon essential for the regulation of a stable microenvironment within multicellular organisms. Traditionally, this process has been attributed to the transfer of extracellular proteins and soluble factors across the intercellular space (Gerdes \& Pepperkok 2013). More recently, researchers have found that exosomes and other EVs also play a significant role in this process (Ciardiello et al. 2016). Exosomes act as shuttles: ferrying proteins, lipids and nucleic acids between cells. Receptors expressed on the exosomal membrane allow them to discriminately interact with specific cellular targets (Corrado et al. 2013) exosomal transfer of growth factor receptors, transcription factors and other regulatory proteins allows cells to influence the gene expression of their neighbors (Peinado et al. 2012, Montermini et al. 2015, Shabbir et al. 2015). Exosomes can also transfer functional RNA between cells (Valadi et al. 2007). mRNA transferred in exosomes can be expressed in target cells, altering the protein expression within those cells (Deregibus et al. 2007, Lee et al. 2012, Tomasoni et al. 2013). The transfer of miRNAs and siRNAs can also alter protein expression in target cells by binding to complementary mRNA in the cytoplasm, inhibiting translation (Guay et al. 2015, Lee et al. 2015b, Zhang et al. 2015). Intercellular transfer of exosomal cargo has been implicated in immunomodulation, initiation of cellular proliferation, angiogenesis, regulation of apoptosis, platelet activation and other phenotypic alterations in targeted cells (Rak 2010, Sheng et al. 2011, Corrado et al. 2013, Tomasoni et al. 2013, Rahman et al. 2014, Shabbir et al. 2015). Such alterations have been associated with both healthy and pathogenic cellular behaviors (BenitoMartin et al. 2015, Ciardiello et al. 2016).

Exosomes facilitate intercellular communication by acting as vectors for paracrine signaling (Tetta et al. 2013, Salido-Guadarrama et al. 2014). Exosomes are believed to be involved in cross-talk between glial cells and neurons, facilitating axon myelination, repair of neurological damage and other essential functions (Krämer-Albers \& White 2011, Lopez-Verrilli \& Court 2012, Sharma et al. 2013). Less beneficially, the transfer of toxic proteins within exosomes in the CNS has been implicated in the development of degenerative neurological disorders 
including Alzheimer's disease and amyotrophic lateral sclerosis (ALS) (Schneider \& Simons 2013). Exosomes secreted from tumor cells are often implicated in cancer metastasis, transporting proteins and miRNAs to influence surrounding tissues to create a supportive microenvironment for the tumor (Hood et al. 2011, Bobrie et al. 2012, Hansen et al. 2014, Lugini et al. 2016).

Exosomes and other EVs can be found in abundance circulating in bodily fluids such as blood, lymph and cerebrospinal fluid. It is believed therefore that exosomes may be able to exert their influence systemically as well as locally, facilitating endocrine communication between distant cells and tissues (McKelvey et al. 2015, Fais et al. 2016). This phenomenon has been well explored as a regulator of the immune response. Exosomes circulating in the blood and lymph are believed to play a significant role in antigen presentation via ingestion by antigen-presenting cells (Raposo et al. 1996, Théry et al. 2009, Alexander et al. 2015). There is also evidence that circulating exosomes may play a role in cancer development (Salido-Guadarrama et al. 2014). However, while circulating EVs, including exosomes, are plentiful, they have been found in multiple studies to possess very short half-lives of $2-5 \mathrm{~min}$ in the blood. It is thought that many of these EVs are quickly digested by macrophages and/or complement interactions or are processed by the spleen and liver (Willekens et al. 2005, Saunderson et al. 2014). The low persistence of circulating exosomes has made their role in non-immune cell endocrine signaling somewhat controversial; however, these same studies have also shown that subpopulations of EVs can persist for up to three hours post injection (Zhuang et al. 2011, Saunderson et al. 2014). In addition, intravenous injection of therapeutic exosomes has been successfully used to deliver treatment in animal models, even when not applied near the therapeutic target site (Graner et al. 2009, Cantaluppi et al. 2012b, Ibrahim et al. 2014).

Exosomes interact with their target cells through multiple mechanisms. These mechanisms typically begin with the binding of ligands expressed on the exosome's surface with compatible receptors on the membrane of the target cell (Hansen et al. 2014, Purushothaman et al. 2016). This interaction can trigger cascading downstream effects in the cellular target. The exosomes of antigenpresenting cells can present MHC-II complexes to primed T-cells in this manner to stimulate an immune reaction (Théry et al. 2009, Bobrie et al. 2011). Similarly, exosomes carrying MCH-I can trigger inhibitory signals in T-cells and natural killer cells, attenuating an immune reaction
(McKelvey et al. 2015). In many cases, a receptor-ligand interaction facilitates the internalization of exosomes into the target cell via receptor-mediated endocytosis or plasma membrane fusion. RNA transfer via exosome requires internalization (McKelvey et al. 2015). In the case of endocytosis, internalization occurs when the exosome is engulfed within an endosome. To release its cargo, the exosome fuses with the limiting membrane, emptying its contents into the cytoplasm prior to lysosomal fusion and digestion (Tian et al. 2010, 2013). Such a mechanism is believed to govern the intake of exosomes by dendritic cells (DC). Through this mechanism, DCs process and present peptides introduced by exosomes to primed CD4+ T-cells (Morelli et al. 2004). Alternatively, through mechanisms not completely understood, the exosome may directly fuse with the plasma membrane of the target cell, releasing its contents into the cell. This form of interaction was observed between melanoma cells and melanoma cell-derived exosomes by Parolini and coworkers (Parolini et al. 2009). A concise visual summary of the different mechanisms of exosome intake is provided in Fig. 2.

\section{Stem cell-derived exosomes protect and support the regeneration of tissues}

Stem cells have generated great interest in the research community due to their potent ability to home to and regenerate damaged tissues (Ilic \& Polak 2011). In many cases, the exosomes secreted from stem cells have been found to mediate this effect. Like their parent cells, exosomes released from pluripotent and multipotent stem cells have been proven to stimulate angiogenesis and cellular regeneration, suppress apoptotic pathways and modulate immunity in chronically damaged tissues both in vivo and in vitro (Derkus et al. 2017). Unlike their parent cells, exosomes are not immunoreactive, can pass through biological barriers and pose no risk of maldifferentiation (Kunter et al. 2007). These properties give exosomes a great deal of potential utility in the field of regenerative medicine as an alternative to stem cell engraftment (George et al. 2011, Ilic \& Polak 2011, Rahavi et al. 2015). Here, we will review some of the recent developments regarding the use of stem cell-derived exosomes as vectors for tissue repair.

The exosomes secreted by pluripotent stem cells hold great therapeutic promise. It has been observed that co-culturing various tissues with progenitor stem cells, such as endothelial progenitor cells (EPCs), has a regenerative and angiogenic effect on these tissues through

Published by Bioscientifica Ltd. 


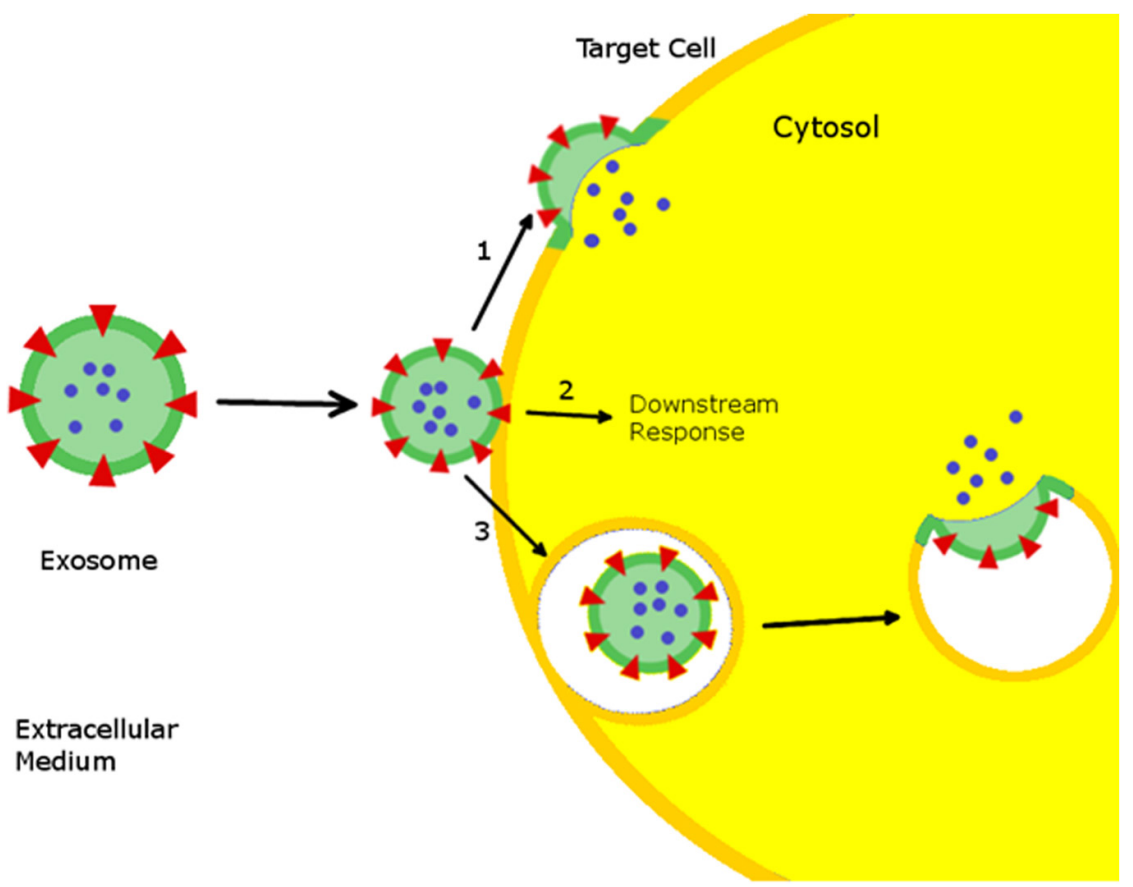

Figure 2

Mechanisms of exosome interaction with target cell. Ligands (triangles) on the surface of the exosomal membrane bind to receptors on the target cell. From there, the receptor-ligand interaction can trigger one of the following: (1) fusion of the exosomal membrane with the cell's plasma membrane, releasing cargo (small circles) into the cytosol, (2) initiation of a downstream signaling cascade in the target cell, (3) endocytosis of the exosome, followed by the fusion of the exosome with the endosome's membrane, releasing cargo (small circles) into the cytosol. a paracrine signaling effect (Yang et al. 2010, George et al. 2011, Luo et al. 2011). Many recent studies suggest that exosomes and other EVs play a significant role in this phenomenon (Cantaluppi et al. 2012a, Lee et al. 2012, Tomasoni et al. 2013, Ibrahim et al. 2014, Tan et al. 2014, Shabbir et al. 2015). Deregibus and coworkers confirmed that EPCs stimulate the proliferation and angiogenesis of endothelial cells, at least in part, through the transfer of RNAs in EVs. In this study, endothelial cells were cultured with EVs taken from EPCs. The endothelial cells in the coculture displayed increased proliferation and reduced apoptosis in vitro. Angiogenesis was also observed both in vitro and in vivo after subcutaneous engraftment in SCID mice. However, pretreating the exosomes with RNase prior to the coculture removed their angiogenic and proliferative effects on endothelial cells (Deregibus et al. 2007). This is evidence that the angiogenic effect of EPCs is caused by the exosomal transfer of RNA. A subsequent study conducted by the same research group observed that EVs taken from EPCs had a similar effect on renal cells (Cantaluppi et al. 2012b). EPC EV injection prevented ischemia-reperfusion injury (IRI)-induced kidney damage in a rat model. The IRI-induced rats displayed reduced renal cell apoptosis, improved tubular cell proliferation and angiogenesis. It was found that this effect was due to the miRNA content of the MVs shifting the renal cells to a regenerative program (Cantaluppi et al. 2012b). miR-126 and miR-296, miRNAs known to be associated with angiogenesis (Wang \& Olson 2009), were found to play a key role in the protective and angiogenic effect of EPC EVs (Cantaluppi et al. 2012b).

Certain adult stem cells, such as mesenchymal stem cells (MSCs), have also demonstrated a supportive effect on other tissues (Luo et al. 2013, Farini et al. 2014). Exosomes may be a mediator of such effects. Gatti and coworkers demonstrated that injections of MSC-derived EVs can protect rats from IRI-induced kidney damage. The injected EVs were found to reduce apoptosis and promote the regeneration of tubular endothelial cells. Treating the EVs with RNase prior to injection greatly reduced these effects, suggesting that RNAs within the EVs were the source (Gatti et al. 2011). In another study, Tan and coworkers were able to use exosomes derived from MSCs to promote the regeneration of hepatic tissue in mice poisoned with carbon tetrachloride. The exosomes stimulated proliferation of hepatocytes by triggering increased expression of IL-6, TNF- $\alpha$ and MIP-2, known priming factors for hepatic proliferation pathways. Proteins associated with these priming factors (IL6ST/gp130, TNFRSF1A/TNFR1 and CXCL2/MIP-2) were all detected within the MSC-derived exosomes. Human growth factor and hepatocyte growth factor receptor were also expressed in the exosomes. Both of these proteins have been previously reported to be powerful stimulators of hepatic regeneration (Tan et al. 2014).

Regenerative treatments using exosomes are also generating promising results in cardiac repair. Ibrahim and coworkers leveraged exosomes from cardiosphere-derived 
cells (CDCs) to induce a proliferative and angiogenic effect on the damaged myocardium of mice afflicted with myocardial infarction. Furthermore, CDCs treated with a sphingomyelinase to prevent exosome formation had no observed proliferative or angiogenic effect on the damaged myocardium when cultured together in vitro. This strongly suggests that exosomes are the method by which CDCs can repair wounded myocardial tissue. CDC-derived exosomes were highly enriched in miR-146a. Direct injection of a mimic of this miRNA had a proliferative effect on rat cardiomyocytes. Additionally, exosomes treated with a miR-146a hairpin inhibitor had a reduced proliferative effect compared to ordinary CDC exosomes when delivered to damaged cardiac tissues. These results suggest that miR-146a was partially responsible for the effect the CDC exosomes (Ibrahim et al. 2014).

Exosomes taken from bone marrow stem cells contain protein and genetic factors that are capable of healing and protecting the tissues of various organs both in vitro and in vivo. There are a number of advantages to using exosomes instead of whole stem cell engraftment for regenerative therapies. Unlike whole cells, exosomes are not immunogenic, can cross biological barriers, and can be easily stored without loss of function. Exosomes also carry no risk of long-term maldifferentiation, a serious concern with stem cell engraftment (Kunter et al. 2007). Thus, exosomes hold great promise as a treatment vector for many illnesses characterized by chronic tissue damage.

\section{Stem cell-derived exosomes and diabetes mellitus}

Due to their demonstrated potential as vehicles for regenerative therapies, exosomes have become a topic of great interest for many labs dedicated to the treatment of chronic illnesses. One illness that stands to benefit from advances in exosome research is diabetes mellitus. Diabetes mellitus is an incurable disease characterized by chronic hyperglycemia due to a patient's reduced ability to produce (type 1) or utilize (type 2) the hormone insulin. Diabetes is becoming increasingly prevalent worldwide, and its complications carry significant morbidity and mortality (Brody 2012, WHO 2016). Controlling the symptoms of diabetes mellitus most often requires daily administration of insulin and other medications for the duration of the patient's life (Brody 2012). This comes at a significant financial burden to patients and to the healthcare establishment (Petersen 2016). Despite advances in treatment, more long-term solutions such as pancreatic islet transplantation pose significant difficulties, making them impractical for most patients (Khosravi-Maharlooei et al. 2015). Findings by various labs in the past decade have suggested that exosomes may be instrumental to the development of novel diabetic treatments. The regenerative and immunomodulatory properties of stem cell derived exosomes could be leveraged as a treatment for serious diabetic complications such as diabetic nephropathy and CNS damage (Jiang et al. 2016, Venkat et al. 2017). Stem cell-derived exosomes may also be the key to protecting the pancreatic islets of type- 1 diabetic (T1D) patients from autoimmune targeting, slowing the disease's progression (Mokarizadeh et al. 2012, Bu et al. 2015). Exosomes could also aid in the angiogenesis and survival of transplanted pancreatic islets, enhancing the efficiency and success rate of the treatment (Cantaluppi et al. 2012a, Kordelas et al. 2014).

\section{Stem cell-derived exosomes can regenerate tissue damage from diabetic complications}

Diabetes mellitus is often accompanied by severe and potentially lethal complications. Diabetic nephropathy affects $30-35 \%$ of all patients suffering from diabetes mellitus and is associated with a 20-40 times increase in mortality (Thomas \& Karalliedde 2015). Diabetic nephropathy is characterized by accumulating hyperglycemia-induced damage of the renal glomerular capillaries. If left unchecked, this damage results in kidney failure necessitating transplantation. This condition is also associated with high blood pressure and a greatly increased risk of heart failure (Schena 2005). There is evidence that exosomes may be able to aid in the treatment of diabetic nephropathy. Studies have found that stem cells have a reparative effect on renal tissues in both diabetic nephropathy and other kidney diseases (Zhang et al. 2013). As previously discussed, the paracrine signaling effect of exosomes may aid in stem cell-mediated regenerative processes, including the repair of renal tissue. In one such study, exosomes secreted from human urinary stem cells (USC) were isolated and injected into the kidneys of nephritic rats. The research group observed a notable decrease in urinary albumin over the course of the experiment, reduced podocyte apoptosis and enhanced glomerular endothelial cell proliferation. The presence of growth factor, transforming growth factor- $\beta 1$, angiogenin, and bone morphogenetic protein-7, all factors that are known to enhance angiogenesis and cell

Published by Bioscientifica Ltd. 
survival, were detected within the USC-derived exosomes (Jiang et al. 2016). These data suggest that stem cellderived exosomes have strong therapeutic potential as a treatment for diabetic kidney damage.

Also, among the complications of diabetes mellitus is a significantly increased occurrence of damage to the CNS (Wrighten et al. 2009). Often this damage is the result ischemic stroke, a condition that diabetic patients are two to six times more likely to experience due to cardiovascular complications. In addition to being more common, strokes experienced by diabetics are often more severe, with a poor prognosis and rate of functional recovery under current treatment protocols (Ergul et al. 2013). MSCs have been found to mediate the functional repair of damaged neuronal tissue, including damage from a stroke, via the transfer of regenerative paracrine factors (Chen et al. 2014). Exosomes derived from MSCs have been demonstrated to have a similar reparative effect on neuronal stroke damage in animal models, transporting miR-133a to promote axonal remodeling and neuronal outgrowth (Xin et al. 2014, Zhang \& Chopp 2016). A recent abstract published by Venkat and coworkers suggests that isolated exosomes derived from MSCs may be an effective treatment for improving the outcomes of diabetic stroke victims specifically (Venkat et al. 2017). In this study, rat models of T2D were subjected to transient middle cerebral artery occlusion (MCAo) to induce ischemic strokes. Rats injected with exosomes isolated from MSCs three days after the stroke experienced reduced hemorrhaging and significantly improved long-term recovery of neurological function and white matter density compared to untreated controls (Venkat et al. 2017). In addition to damage caused by strokes, diabetic patients have a significantly increased likelihood of developing cognitive impairment due to structural damage of the CNS. This damage is thought to be a result of vascular abnormalities and oxidative stress in the CNS caused by chronic hyperglycemia (Wrighten et al. 2009). In a study published by Nakano and coworkers, exosomes derived from MSCs were found to ameliorate CNS symptoms in diabetic rats. Diabetic cognitively impaired, mice injected with the exosomes displayed improved cognition, learning and synaptic density within days of exosome injection compared to the untreated diabetic controls. It was concluded that the exosomes repaired oxidative damage in neurons and astrocytes to restore cognitive function in the diabetic animals (Nakano et al. 2016). These results demonstrate the potential of exosome-based therapies as a treatment for CNS damage prevalent in diabetic patients. Treating
CNS damage has long been a challenge for even the most advanced treatment techniques. Novel therapeutic strategies using exosomes to improve patient outcomes would be of tremendous benefit to both diabetic and nondiabetic patients suffering from CNS injury.

\section{Stem cell-derived exosomes may improve treatment outcomes for T1D patients}

Diabetes mellitus type 1 (T1D) is an autoimmune disorder characterized by immune-associated destruction of pancreatic islet $\beta$-cells, resulting in greatly reduced insulin secretion and hyperglycemia. Sufferers of this heritable disorder are often dependent on frequent insulin injections to prevent hyperglycemia, along with other medications to manage T1D's often debilitating symptoms (Atkinson et al. 2014, Miller et al. 2015). Exosomes derived from stem cells and certain antigen-presenting cells (APCs) have shown the ability to reduce immune activity by promoting the proliferation of regulatory T-cells and the apoptosis of autoreactive T-cells (Mokarizadeh et al. 2012, Robbins 2014). These immunoregulatory properties have been successfully applied to treat various autoimmune disorders such as myasthenia gravis in pre-clinical models (Bu et al. 2015). These findings suggest that it may be possible to utilize stem cell-derived exosomes to slow or stop the progression of T1D, preserving pancreatic islet cells and the patient's insulin independence. There is even a possibility that the reparative properties of stem cell-derived exosomes could cause functional recovery of the islets. Multiple clinical trials were able to achieve this effect through the engraftment of whole hematopoietic stem cells in early-stage T1D patients (D'Addio et al. 2014). Stem cell-derived exosome injections could potentially be equally effective, while not requiring immunosuppressants to prevent graft rejection. However, near total destruction of pancreatic $\beta$ cells is quick to occur (Atkinson et al. 2014), so such treatments would have to be administered very early in the disease's progression if insulin function is to be retained.

One of the most promising treatments for T1D is pancreatic islet transplantation. This procedure consists of the transplantation of healthy pancreatic islets from recently deceased donors into T1D patients. This therapy has allowed many patients to regain temporary insulin independence (Kuise \& Noguchi 2011). However, many challenges remain before this treatment can become suitable for widespread use. Pancreatic islet $\beta$-cells tend to rapidly undergo necrosis and apoptosis in vitro upon http://jme.endocrinology-journals.org DOI: 10.1530/JME-17-0080
() 2017 Society for Endocrinology Printed in Great Britain
Published by Bioscientifica Ltd 
harvest and often continue to do so after engraftment in a new host. This is thought to be brought about by the disruption of the islet's proper microenvironment and a lack of vascular support. Host immune rejection is also a significant aggravating factor (Rother \& Harlan 2004). To compensate for the high rate of islet loss, at least two donors are required for each procedure. Even then, most recipients lose insulin independence within five years (Rother \& Harlan 2004, Jiang \& Morahan 2014). Our lab has found that co-culturing islets with BMSCs can greatly improve islet vascularization and reduce apoptosis, resulting in increased survival and function of islet $\beta$-cells both in vitro and after engraftment in animal models (Luo et al. 2011, 2013, 2015). There is evidence that stem cell-derived exosomes mediate this effect. Cantaluppi and coworkers used EVs taken from EPCs to promote angiogenesis and regeneration when cultured with pancreatic islets in vivo and in vitro. These EPC-derived EVs contained miR-126 and miR-296, two miRNAs that had been previously described by the same research group to promote angiogenesis and proliferation of renal endothelial cells. When these EVs were treated with RNase, the angiogenic effect on the islet endothelium was reduced, suggesting that RNAs contained within the EVs were responsible for the observed angiogenesis (Cantaluppi et al. 2012a). Furthermore, limited clinical evidence shows that exosomes derived from MSCs can act to suppress immune targeting of allogeneic grafts, effectively treating graft vs host disease (Kordelas et al. 2014). Based on these findings, it is likely that exosomes released by stem cells are at least partially responsible for the supportive effect whole stem cells have on islet $\beta$-cells. Therapies incorporating exosomes such as these, which contain anti-apoptotic, regenerative, angiogenic and immunomodulatory factors could make islet transplantation a more practical and appealing option for patients suffering from T1D, extending the functional life of an islet graft while reducing the need for immunosuppressive treatments.

\section{Conclusions and future perspective}

With a more complete understanding of the mechanisms driving exosome formation, exosomes could be engineered as vectors for the targeted delivery of molecular therapies. In 2011, Alverez-Erviti and coworkers published a study demonstrating the potential of such a technique (AlverezErviti et al. 2011). Exosomes have the advantage of being nonimmunogenic, highly resilient and capable of acting both locally and systemically. These advantages make exosomes a potentially safer and more effective alternative to conventional viral vectors (Lee et al. 2012). Proteins and RNA found to aid in tissue regeneration could be packaged into specially engineered exosomes expressing ligands facilitating attachment to the therapeutic target. Injection of these exosomes would, in theory, allow for the discriminate delivery of medicine directly into specific target cells. Such therapies could one day be administered to diabetic patients suffering from nephropathy or CNS damage to stimulate cellular regeneration. It could also be of benefit as a supportive treatment for pancreatic islet transplant recipients, lengthening insulin independence and reducing the patients' dependence on immunosuppressive medication. The long-term efficacy and safety of such a treatment would first have to be established.

Exosome research is still in its early stages. No fullscale clinical trials using exosome-based regenerative therapies have yet been conducted. Progress is dependent on the development of a greater understanding of the mechanisms governing exosome formation and signaling. Gaps in mechanistic knowledge, inconsistent nomenclature, and a lack of standardized characterization techniques remain a challenge for exosome research going forward. Overcoming these obstacles will pave the way for clinical trials and will allow for a wide range of new discoveries and treatments for a variety of disorders. Exosomes have the potential to provide all the benefits of stem cell-based regenerative therapies without the dangers of maldifferentiation or immune rejection. Such treatments could revolutionize the field of regenerative medicine with applications for the treatment of many common disorders, including diabetes mellitus.

Declaration of interest

The author declares that there is no conflict of interest that could be perceived as prejudicing the impartiality of this review.

Funding

This work was funded by grants from the US National Institutes of Health (NIH) 1R01DK097380-01A1 (L L) and National Center for Research Resources (COBRE, 5P20RR018757-10), Juvenile Diabetes Research Foundation International (JDRF) Foundation 1-2007-180 (L L) and Roger Williams Hospital Research fund (L L).

\section{References}

Alexander M, Hu R, Runtsch MC, Kagele DA, Mosbruger TL, Tolmachova T, Seabra MC, Round JL, Ward DM \& O'Connell RM 2015 Exosome-

Published by Bioscientifica Ltd. 
delivered microRNAs modulate the inflammatory response to endotoxin. Nature Communications 6 7321. (doi:10.1038/ ncomms8321)

Alvarez-Erviti L, Seow Y, Yin H, Betts C, Lakhal S \& Wood MJA 2011 Delivery of siRNA to the mouse brain by systemic injection of targeted exosomes. Nature Biotechnology 29 341-345. (doi:10.1038/ nbt.1807)

Atkinson MA, Eisenbarth GS \& Michels AW 2014 Type 1 diabetes. Lancet 383 69-82. (doi:10.1016/S0140-6736(13)60591-7)

Benito-Martin A, Di Giannatale A, Ceder S \& Peinado Hc 2015 The new deal: a potential role for secreted vesicles in innate immunity and tumor progression. Frontiers in Immunology 6 66. (doi:10.3389/ fimmu.2015.00066)

Bobrie A, Colombo M, Raposo G \& Théry C 2011 Exosome secretion: molecular mechanisms and roles in immune responses. Traffic $\mathbf{1 2}$ 1659-1668. (doi:10.1111/j.1600-0854.2011.01225.x)

Bobrie A, Krumeich S, Reyal F, Recchi C, Moita LF, Seabra MC, Ostrowski M \& Théry C 2012 Rab27a supports exosome-dependent and -independent mechanisms that modify the tumor microenvironment and can promote tumor progression. Cancer Research 72 4920-4930. (doi:10.1158/0008-5472.CAN-12-0925)

Brody H 2012 Diabetes. Nature 485 S1. (doi:10.1038/485S1a)

Bu N, Wu H-Q, Zhang G-L, Zhan S-Q, Zhang R, Fan Q-Y, Li Y-L, Zhai Y-F \& Ren H-W 2015 Immature dendritic cell exosomes suppress experimental autoimmune myasthenia gravis. Journal of Neuroimmunology 285 71-75. (doi:10.1016/j.jneuroim.2015.04.009)

Cantaluppi V, Biancone L, Figliolini F, Beltramo S, Medica D, Deregibus MC, Galimi F, Romagnoli R, Salizzoni M, Tetta C, et al. 2012a Microvesicles derived from endothelial progenitor cells enhance neoangiogenesis of human pancreatic islets. Cell Transplantation 21 1305-1320. (doi:10.3727/096368911X627534)

Cantaluppi V, Gatti S, Medica D, Figliolini F, Bruno S, Deregibus MC, Sordi A, Biancone L, Tetta C \& Camussi G 2012b Microvesicles derived from endothelial progenitor cells protect the kidney from ischemia-reperfusion injury by microRNA-dependent reprogramming of resident renal cells. Kidney International 82 412-427. (doi:10.1038/ ki.2012.105)

Chen J, Venkat P, Zacharek A \& Chopp M 2014 Neurorestorative therapy for stroke. Frontiers in Human Neuroscience 8 382. (doi:10.3389/ fnhum.2014.00382)

Ciardiello C, Cavallini L, Spinelli C, Yang J, Reis-Sobreiro M, Candia PD, Minciacchi VR \& Di Vizio D 2016 Focus on extracellular vesicles: new frontiers of cell-to-cell communication in cancer. International Journal of Molecular Sciences 17 175. (doi:10.3390/ijms17020175)

Cocucci E \& Meldolesi J 2015 Ectosomes and exosomes: shedding the confusion between extracellular vesicles. Trends in Cell Biology $\mathbf{2 5}$ 364-372. (doi:10.1016/j.tcb.2015.01.004)

Colombo M, Moita C, van Niel G, Kowal J, Vigneron J, Benaroch P, Manel N, Moita LF, Théry C, Raposo G, et al. 2013 Analysis of ESCRT functions in exosome biogenesis, composition and secretion highlights the heterogeneity of extracellular vesicles. Journal of Cell Science 126 5553-5565. (doi:10.1242/jcs.128868)

Corrado C, Raimondo S, Chiesi A, Ciccia F, De Leo G \& Alessandro R 2013 Exosomes as intercellular signaling organelles involved in health and disease: basic science and clinical applications. International Journal of Molecular Sciences 14 5338-5366. (doi:10.3390/ ijms14035338)

D'Addio F, Valderrama Vasquez A, Ben Nasr M, Franek E, Zhu D, Li L, Ning G, Snarski E \& Fiorina P 2014 Autologous nonmyeloablative hematopoietic stem cell transplantation in new-onset type 1 diabetes: a multicenter analysis. Diabetes 63 3041-3046. (doi:10.2337/db14-0295)

De Toro J, Herschlik L, Waldner C \& Mongini C 2015 Emerging roles of exosomes in normal and pathological conditions: new insights for diagnosis and therapeutic applications. Frontiers in Immunology 6203. (doi:10.3389/fimmu.2015.00203)
Deregibus MC, Cantaluppi V, Calogero R, Lo Iacono M, Tetta C, Biancone L, Bruno S, Bussolati B \& Camussi G 2007 Endothelial progenitor cell-derived microvesicles activate an angiogenic program in endothelial cells by a horizontal transfer of mRNA. Blood 110 2440-2448. (doi:10.1182/blood-2007-03-078709)

Derkus B, Emregul KC \& Emregul E 2017 A new approach in stem cell research-exosomes: their mechanism of action via cellular pathways. Cell Biology International 41 466-475. (doi:10.1002/ cbin.10742)

Ergul A, Kelly-Cobbs A, Abdalla M \& Fagan SC 2013 Cerebrovascular complications of diabetes: focus on stroke. Endocrine, Metabolic and Immune Disorders Drug Targets 12 148-158. (doi:10.2174/1871530128 00493477)

Fais S, O'Driscoll L, Borras FE, Buzas E, Camussi G, Cappello F, Carvalho J, Cordeiro Da Silva A, Del Portillo H, El Andaloussi S, et al. 2016 Evidence-based clinical use of nanoscale extracellular vesicles in nanomedicine. ACS Nano 10 3886-3899. (doi:10.1021/ acsnano.5b08015)

Farini A, Sitzia C, Erratico S, Meregalli M \& Torrente Y 2014 Clinical applications of mesenchymal stem cells in chronic diseases. Stem Cells International 2014 article ID 306573. (doi:10.1155/2014/306573)

Gatti S, Bruno S, Deregibus MC, Sordi A, Cantaluppi V, Tetta C \& Camussi G 2011 Microvesicles derived from human adult mesenchymal stem cells protect against ischaemia-reperfusioninduced acute and chronic kidney injury. Nephrology Dialysis Transplantation 26 1474-1483. (doi:10.1093/ndt/gfr015)

George AL, Bangalore-Prakash P, Rajoria S, Suriano R, Shanmugam A, Mittelman A \& Tiwari RK 2011 Endothelial progenitor cell biology in disease and tissue regeneration. Journal of Hematology and Oncology 4 24. (doi:10.1186/1756-8722-4-24)

Gerdes H-H \& Pepperkok R 2013 Cell-to-cell communication: current views and future perspectives. Cell and Tissue Research 352 1-3. (doi:10.1007/s00441-013-1590-1)

Graner MW, Alzate O, Dechkovskaia AM, Keene JD, Sampson JH, Mitchell DA \& Bigner DD 2009 Proteomic and immunologic analyses of brain tumor exosomes. FASEB Journal 23 1541-1557. (doi:10.1096/fj.08-122184)

Guay C, Menoud V, Rome S \& Regazzi R 2015 Horizontal transfer of exosomal microRNAs transduce apoptotic signals between pancreatic beta-cells. Cell Communication and Signaling 13 17. (doi:10.1186/ s12964-015-0097-7)

Guduric-Fuchs J, O'Connor A, Camp B, O'Neill CL, Medina RJ \& Simpson DA 2012 Selective extracellular vesicle-mediated export of an overlapping set of microRNAs from multiple cell types. BMC Genomics 13 357. (doi:10.1186/1471-2164-13-357)

Hansen HP, Engels H-M, Dams M, Paes Leme AF, Pauletti BA, Simhadri VL, Dürkop H, Reiners KS, Barnert S, Engert A, et al. 2014 Protrusionguided extracellular vesicles mediate CD30 trans-signalling in the microenvironment of Hodgkin's lymphoma. Journal of Pathology 232 405-414. (doi:10.1002/path.4306)

Harding CV, Heuser JE \& Stahl PD 2013 Exosomes: looking back three decades and into the future. Journal of Cell Biology 200 367-371. (doi:10.1083/jcb.201212113)

Hood JL, San Roman S \& Wickline SA 2011 Exosomes released by melanoma cells prepare sentinel lymph nodes for tumor metastasis. Cancer Research 71 3792-3801. (doi:10.1158/0008-5472.CAN-10-4455)

Ibrahim AGE, Cheng K \& Marbán E 2014 Exosomes as critical agents of cardiac regeneration triggered by cell therapy. Stem Cell Reports 2 606-619. (doi:10.1016/j.stemcr.2014.04.006)

Ilic D \& Polak JM 2011 Stem cells in regenerative medicine: introduction. British Medical Bulletin 98 117-126. (doi:10.1093/bmb/ ldr012)

Janas T, Janas MM, Sapoń K \& Janas T 2015 Mechanisms of RNA loading into exosomes. FEBS Letters 589 1391-1398. (doi:10.1016/j. febslet.2015.04.036) 
Jiang F-X \& Morahan G 2014 Pancreatic stem cells remain unresolved Stem Cells and Development 23 1-31. (doi:10.1089/scd.2014.0214)

Jiang Z-Z, Liu Y-M, Niu X, Yin J-Y, Hu B, Guo S-C, Fan Y, Wang Y \& Wang N-S 2016 Exosomes secreted by human urine-derived stem cells could prevent kidney complications from type I diabetes in rats. Stem Cell Research and Therapy 7 24. (doi:10.1186/s13287-016-0287-2)

Kalra H, Drummen GPC \& Mathivanan S 2016 Focus on extracellular vesicles: introducing the next small big thing. International Journal of Molecular Sciences 17 170. (doi:10.3390/ijms17020170)

Kastelowitz N \& Yin H 2014 Exosomes and microvesicles: identification and targeting by particle size and lipid chemical probes. ChemBioChem 15 923-928 (doi:10.1002/cbic.201400043)

Khosravi-Maharlooei M, Hajizadeh-Saffar E, Tahamtani Y, Basiri M, Montazeri L, Khalooghi K, Ashtiani MK, Farrokhi A, Aghdami N, Hashemi Nejad AS, et al. 2015 Therapy of endocrine disease: Islet transplantation for type 1 diabetes: so close and yet so far away. European Journal of Endocrinology 173 R165-R183. (doi:10.1530/EJE15-0094)

Kordelas L, Rebmann V, Ludwig A-k, Radtke S, Ruesing J, Doeppner TR, Epple M, Horn PA, Beelen DW \& Giebel B 2014 MSC-derived exosomes: a novel tool to treat therapy-refractory graft-versus-host disease. Leukemia 28 970-973. (doi:10.1038/leu.2014.41)

Krämer-Albers E-M \& White R 2011 From axon-glial signalling to myelination: the integrating role of oligodendroglial Fyn kinase. Cellular and Molecular Life Sciences 68 2003-2012. (doi:10.1007/ s00018-010-0616-z)

Kuise T \& Noguchi H 2011 Recent progress in pancreatic islet transplantation. World Journal of Transplantation 1 13-18. (doi:10.5500/wjt.v1.i1.13)

Kunter U, Rong S, Boor P, Eitner F, Müller-Newen G, Djuric Z, van Roeyen CR, Konieczny A, Ostendorf T, Villa L, et al. 2007 Mesenchymal stem cells prevent progressive experimental renal failure but maldifferentiate into glomerular adipocytes. Journal of the American Society of Nephrology 18 1754-1764. (doi:10.1681/ ASN.2007010044)

Lee Y, El Andaloussi S \& Wood MJA 2012 Exosomes and microvesicles: extracellular vesicles for genetic information transfer and gene therapy. Human Molecular Genetics 21 R125-134. (doi:10.1093/hmg/ dds317)

Lee JC, Zhao JT, Gundara J, Serpell J, Bach LA \& Sidhu S 2015a Papillary thyroid cancer-derived exosomes contain miRNA-146b and miRNA222. Journal of Surgical Research 196 39-48. (doi:10.1016/j. jss.2015.02.027)

Lee YS, Lim YS, Lee JC, Wang SG, Park HY, Kim SY \& Lee BJ 2015b Differential expression levels of plasma-derived miR-146b and miR155 in papillary thyroid cancer. Oral Oncology 51 77-83. (doi:10.1016/j.oraloncology.2014.10.006)

Lopez-Verrilli MA \& Court FA 2012 Transfer of vesicles from Schwann cells to axons: a novel mechanism of communication in the peripheral nervous system. Frontiers in Physiology 3205. (doi:10.3389/fphys.2012.00205)

Lugini L, Valtieri M, Federici C, Cecchetti S, Meschini S, Condello M, Signore M \& Fais S 2016 Exosomes from human colorectal cancer induce a tumor-like behavior in colonic mesenchymal stromal cells. Oncotarget 7 50086-50098. (doi:10.18632/oncotarget.10574)

Luo JZQ, Xiong F, Al-Homsia S, Roy T \& Luo LG 2011 Human BM stem cells initiate angiogenesis in human islets in vitro. Bone Marrow Transplantation 46 1128-1137. (doi:10.1038/bmt.2010.278)

Luo L, Badiavas E, Luo JZ \& Maizel A 2013 Allogeneic bone marrow supports human islet $\boldsymbol{\beta}$ cell survival and function over six months. Biochemical and Biophysical Research Communications 361 859-864. (doi:10.1016/j.bbrc.2007.07.105)

Luo LG, Xiong F, Ravassard P \& Luo JZ 2015 Human bone marrow subpopulations sustain human islet function and viability in vitro HHS public access. British Journal of Medicine and Medical Research 8 576-587. (doi:10.9734/BJMMR/2015/17536)
McKelvey KJ, Powell KL, Ashton AW, Morris JM \& McCracken SA 2015 Exosomes: mechanisms of uptake. Journal of Circulating Biomarkers 47. (doi:10.5772/61186)

Miller KM, Foster NC, Beck RW, Bergensta RM, DuBose SN, DiMeglio LA, Maahs DM \& Tamborlane WV 2015 Current state of type 1 diabetes treatment in the U.S.: updated data from the t1d exchange clinic registry. Diabetes Care 38 971-978. (doi:10.2337/dc15-0078)

Mokarizadeh A, Delirezh N, Morshedi A, Mosayebi G, Farshid AA \& Mardani K 2012 Microvesicles derived from mesenchymal stem cells: potent organelles for induction of tolerogenic signaling. Immunology Letters 147 47-54. (doi:10.1016/j.imlet.2012.06.001)

Montermini L, Meehan B, Garnier D, Lee WJ, Lee TH, Guha A, Al-Nedawi K \& Rak J 2015 Inhibition of oncogenic epidermal growth factor receptor kinase triggers release of exosome-like extracellular vesicles and impacts their phosphoprotein and DNA content. Journal of Biological Chemistry 290 24534-24546. (doi:10.1074/jbc. M115.679217)

Morelli AE, Larregina AT, Shufesky WJ, Sullivan MLG, Stolz DB, Papworth GD, Zahorchak AF, Logar AJ, Wang Z, Watkins SC, et al. 2004 Endocytosis, intracellular sorting, and processing of exosomes by dendritic cells. Blood 104 3257-3266. (doi:10.1182/blood-200403-0824)

Musante L, Tataruch DE \& Holthofer H 2014 Use and isolation of urinary exosomes as biomarkers for diabetic nephropathy. Frontiers in Endocrinology 5 149. (doi:10.3389/fendo.2014.00149)

Nakano M, Nagaishi K, Konari N, Saito Y, Chikenji T, Mizue Y \& Fujimiya M 2016 Bone marrow-derived mesenchymal stem cells improve diabetes-induced cognitive impairment by exosome transfer into damaged neurons and astrocytes. Scientific Reports 624805 . (doi:10.1038/srep24805)

Ostrowski M, Carmo NB, Krumeich S, Fanget I, Raposo G, Savina A, Moita CF, Schauer K, Hume AN, Freitas RP, et al. 2010 Rab27a and Rab27b control different steps of the exosome secretion pathway. Nature Cell Biology 12 19-30. (doi:10.1038/ncb2000)

Pan B-T \& Johnstone RM 1983 Fate of the transferrin receptor during maturation of sheep reticulocytes in vitro: selective externalization of the receptor. Cell 33 967-978. (doi:10.1016/0092-8674(83)90040-5)

Parolini I, Federici C, Raggi C, Lugini L, Palleschi S, De Milito A, Coscia C, Iessi E, Logozzi M, Molinari A, et al. 2009 Microenvironmental pH is a key factor for exosome traffic in tumor cells. Journal of Biological Chemistry 284 34211-34222. (doi:10.1074/jbc.M109.041152)

Peinado H, Alečković M, Lavotshkin S, Matei I, Costa-Silva B, MorenoBueno G, Hergueta-Redondo M, Williams C, García-Santos G, Ghajar C, et al. 2012 Melanoma exosomes educate bone marrow progenitor cells toward a pro-metastatic phenotype through MET. Nature Medicine 18 883-891. (doi:10.1038/nm.2753)

Petersen M 2016 Economic costs of diabetes in the U.S. in 2012. Diabetes Care 39 1033-1046. (doi:10.2337/dc12-2625)

Purushothaman A, Bandari SK, Liu J, Mobley JA, Brown EA \& Sanderson RD 2016 Fibronectin on the surface of myeloma cell-derived exosomes mediates exosome-cell interactions. Journal of Biological Chemistry 291 1652-1663. (doi:10.1074/jbc.M115.686295)

Rahavi H, Hashemi SM, Soleimani M, Mohammadi J \& Tajik N 2015 Adipose tissue-derived mesenchymal stem cells exert in vitro immunomodulatory and beta cell protective functions in streptozotocin-induced diabetic mice model. Journal of Diabetes Research 2015 878535. (doi:10.1155/2015/878535)

Rahman MJ, Regn D, Bashratyan R \& Dai YD 2014 Exosomes released by islet-derived mesenchymal stem cells trigger autoimmune responses in NOD mice. Diabetes 63 1008-1020. (doi:10.2337/db13-0859)

Rak J 2010 Microparticles in cancer. Seminars in Thrombosis and Hemostasis 36 888-906. (doi:10.1055/s-0030-1267043)

Raposo G, Nijman HW, Stoorvogel W, Leijendekker R, Hardingfl C, Melief CJM \& Geuze HJ 1996 B lymphocytes secrete antigenpresenting vesicles. Journal of Experimental Medicine 183 1161-1172. (doi:10.1084/jem.183.3.1161)

Published by Bioscientifica Ltd. 
Raposo G \& Stoorvogel W 2013 Extracellular vesicles: exosomes, microvesicles, and friends. Journal of Cell Biology 200 373-383. (doi:10.1083/jcb.201211138)

Robbins PD 2014 Regulation of immune responses by extracellular vesicles. Nature Reviews: Immunology 14 195-208. (doi:10.1038/nri3622)

Rother KI \& Harlan DM 2004 Challenges facing islet transplantation for the treatment of type 1 diabetes mellitus. Journal of Clinical Investigation 114 877-883. (doi:10.1172/JCI200423235)

Salido-Guadarrama In, Romero-Cordoba S, Peralta-Zaragoza O, HidalgoMiranda A \& RodrÃguez-Dorantes M 2014 MicroRNAs transported by exosomes in body fluids as mediators of intercellular communication in cancer. OncoTargets and Therapy 7 1327-1338. (doi:10.2147/OTT.S61562)

Saunderson SC, Dunn AC, Crocker PR \& McLellan AD 2014 CD169 mediates the capture of exosomes in spleen and lymph node. Blood 123 208-216. (doi:10.1182/blood-2013-03-489732)

Schena FP 2005 Pathogenetic mechanisms of diabetic nephropathy. Journal of the American Society of Nephrology 16 S30-S33. (doi:10.1681/ASN.2004110970)

Schneider A \& Simons M 2013 Exosomes: vesicular carriers for intercellular communication in neurodegenerative disorders. Cell and Tissue Research 352 33-47. (doi:10.1007/s00441-012-1428-2)

Shabbir A, Cox A, Rodriguez-Menocal L, Salgado M \& Badiavas EV 2015 Mesenchymal stem cell exosomes induce proliferation and migration of normal and chronic wound fibroblasts, and enhance angiogenesis in vitro. Stem Cells and Development 24 1635-1647. (doi:10.1089/ scd.2014.0316)

Sharma P, Schiapparelli L \& Cline HT 2013 Exosomes function in cell-cell communication during brain circuit development. Current Opinion in Neurobiology 23 997-1004. (doi:10.1016/j.conb.2013.1008.1005)

Sheng H, Hassanali S, Nugent C, Wen L, Hamilton-Williams E, Dias P \& Dai YD 2011 Insulinoma-released exosomes or microparticles are immunostimulatory and can activate autoreactive T cells spontaneously developed in non-obese diabetes mice1. Journal of Immunology 187 1591-1600. (doi:10.4049/jimmunol.1100231)

Simons M \& Raposo G 2009 Exosomes-vesicular carriers for intercellular communication. Current Opinion in Cell Biology 21 575-581. (doi:10.1016/j.ceb.2009.03.007)

Tan CY, Lai RC, Wong W, Dan YY, Lim S-K \& Ho HK 2014 Mesenchymal stem cell-derived exosomes promote hepatic regeneration in drug-induced liver injury models. Stem Cell Research and Therapy 5 76. (doi:10.1186/scrt465)

Tetta C, Ghigo E, Silengo L, Deregibus MC \& Camussi G 2013 Extracellular vesicles as an emerging mechanism of cell-to-cell communication. Endocrine 44 11-19. (doi:10.1007/s12020-012-9839-0)

Thomas S \& Karalliedde J 2015 Diabetic nephropathy. Medicine 43 20-25. (doi:10.1016/j.mpmed.2014.10.007)

Théry C, Ostrowski M \& Segura E 2009 Membrane vesicles as conveyors of immune responses. Nature Reviews: Immunology 9 581-593. (doi:10.1038/nri2567)

Tian T, Wang Y, Wang H, Zhu Z \& Xiao Z 2010 Visualizing of the cellular uptake and intracellular trafficking of exosomes by live-cell microscopy. Journal of Cellular Biochemistry 111 488-496. (doi:10.1002/jcb.22733)

Tian T, Zhu YL, Hu FH, Wang YY, Huang NP \& Xiao ZD 2013 Dynamics of exosome internalization and trafficking. Journal of Cellular Physiology 228 1487-1495. (doi:10.1002/jcp.24304)

Tomasoni S, Longaretti L, Rota C, Morigi M, Conti S, Gotti E, Capelli C, Introna M, Remuzzi G \& Benigni A 2013 Transfer of growth factor receptor mRNA via exosomes unravels the regenerative effect of mesenchymal stem cells. Stem Cells and Development 22 772-780. (doi:10.1089/scd.2012.0266)

Valadi H, Ekström K, Bossios A, Sjöstrand M, Lee JJ \& Lötvall JO 2007 Exosome-mediated transfer of mRNAs and microRNAs is a novel mechanism of genetic exchange between cells. Nature Cell Biology 9 654-659. (doi:10.1038/ncb1596)

Venkat P, Chopp M, Zacharek A \& Chen J 2017 Abstract WMP46: exosomes derived from bone marrow mesenchymal stem cells of type two diabetes rats promotes neurorestoration after stroke in type two diabetic rats. Stroke $\mathbf{4 8}$ AWMP46.

Wang S \& Olson EN 2009 AngiomiRs-key regulators of angiogenesis. Current Opinion in Genetics and Development 19 205-211. (doi:10.1016/j.gde.2009.04.002)

WHO 2016 Global Report on Diabetes. Geneva, Switzerland: World Health Organization. (available at: http://www.who.int/diabetes/globalreport/en/)

Willekens FLA, Werre JM, Kruijt JK, Roerdinkholder-Stoelwinder B, Groenen-Döpp YAM, van den Bos AG, Bosman GJCGM \& van Berkel TJC 2005 Liver Kupffer cells rapidly remove red blood cell derived vesicles from the circulation by scavenger receptors. Blood $\mathbf{1 0 5}$ 2141-2145. (doi:10.1182/blood-2004-04-1578)

Wrighten SA, Piroli GG, Grillo CA \& Reagan LP 2009 A look inside the diabetic brain: contributors to diabetes-induced brain aging. Biochimica et Biophysica Acta 1792 444-453. (doi:10.1016/j. bbadis.2008.10.013)

Xin H, Li Y, Liu Z, Wang X, Shang X, Cui Y, Zhang ZG \& Chopp M 2014 MiR-133b promotes neural plasticity and functional recovery after treatment of stroke with multipotent mesenchymal stromal cells in rats via transfer of exosome-enriched extracellular particles. Stem Cells 31 2737-2746. (doi:10.1002/stem.1409)

Yang Z, von Ballmoos MW, Faessler D, Voelzmann J, Ortmann J, Diehm N, Kalka-Moll W, Baumgartner I, Di Santo S \& Kalka C 2010 Paracrine factors secreted by endothelial progenitor cells prevent oxidative stressinduced apoptosis of mature endothelial cells. Atherosclerosis 211 103-109. (doi:10.1016/j.atherosclerosis.2010.02.022)

Yu B, Zhang X \& Li X 2014 Exosomes derived from mesenchymal stem cells. International Journal of Molecular Sciences 15 4142-4157. (doi:10.3390/ijms15034142)

Yáñez-Mó M, Siljander PR-M, Andreu Z, Zavec AB, Borràs FE, Buzas EI, Buzas K, Casal E, Cappello F, Carvalho J, et al. 2015 Biological properties of extracellular vesicles and their physiological functions. Journal of Extracellular Vesicles 4 27066. (doi:10.3402/jev.v4.27066)

Zhang L, Li K, Liu X, Li D, Luo C, Fu B, Cui S, Zhu F, Zhao RC \& Chen X 2013 Repeated systemic administration of human adipose-derived stem cells attenuates overt diabetic nephropathy in rats. Stem Cells and Development 22 3074-3086. (doi:10.1089/scd.2013.0142)

Zhang J, Li S, Li L, Li M, Guo C, Yao J \& Mi S 2015 Exosome and exosomal microRNA: trafficking, sorting, and function. Genomics, Proteomics and Bioinformatics 13 17-24. (doi:10.1016/j. gpb.2015.02.001)

Zhang ZG \& Chopp M 2016 Exosomes in stroke pathogenesis and therapy. Journal of Clinical Investigation 126 1190-1197. (doi:10.1172/ JCI81133)

Zhuang X, Xiang X, Grizzle W, Sun D, Zhang S, Axtell RC, Ju S, Mu J, Zhang L, Steinman L, et al. 2011 Treatment of brain inflammatory diseases by delivering exosome encapsulated anti-inflammatory drugs from the nasal region to the brain. Molecular Therapy 19 1769-1779. (doi:10.1038/mt.2011.164)

Received in final form 24 July 2017

Accepted 23 August 2017

Accepted Preprint published online 23 August 2017 http://jme.endocrinology-journals.org

DOI: 10.1530/JME-17-0080
๑) 2017 Society for Endocrinology Printed in Great Britain
Published by Bioscientifica Ltd 